\title{
Seasonal reproduction of a tropical bat, Anoura geoffroyi, in relation to photoperiod
}

\author{
P. D. Heideman ${ }^{1}$, P. Deoraj ${ }^{2 *}$ and F. H. Bronson ${ }^{1}$ \\ ${ }^{1}$ Institute of Reproductive Biology, Department of Zoology, University of Texas at Austin, Austin, \\ TX 78712, USA; and ${ }^{2}$ Department of Zoology, The University of the West Indies, St Augustine, \\ Trinidad and Tobago
}

\begin{abstract}
Summary. Anoura geoffroyi (Chiroptera, Phyllostomidae, Glossophaginae), Geoffroy's hairy-legged long-tongued bat, were collected from September 1984 to August 1985, and these bats were found to breed seasonally in the wild on Trinidad, West Indies, at $10^{\circ} \mathrm{N}$ latitude. Histological examination of these samples indicated that females became pregnant in July or August, and young were born in late November or early December. The testes and epididymides were small from September to mid-April, increased threefold in weight between mid-April and late May, reached a peak weight in July, and decreased in weight in August. Spermatogenesis occurred throughout the testes of males captured from May to August. In 1990, the timing of parturition in females that gave birth in the laboratory to young conceived in the wild was similar to the timing in the field in 1984-1985. Groups of 10-13 males were subjected in the laboratory to (i) a gradually changing, civil twilight photoperiod that mimicked the natural cycle of annual change at $10^{\circ} \mathrm{N}$ latitude, (ii) the same gradually changing cycle of photoperiod accelerated to a six-month period, or (iii) a constant photoperiod (light 12:54 h: dark 11:06 h). These treatments began in mid-December, four months before the initiation of testicular recrudescence in the wild. In all three groups, testicular volume remained low until April, and then increased two- to threefold between late April and late June, rising to a peak in July, as occurred in the wild. Thus photoperiodic cues are not required for testicular recrudescence during the six months before peak testis size, nor is the timing of recrudescence sensitive to the accelerated pattern of photoperiodic change provided here. It is possible that other photoperiod treatments might affect reproductive timing in this species, or that other portions of the reproductive cycle are sensitive to photoperiod.
\end{abstract}

Keywords: photoperiod; tropical, seasonal breeding; bat; Phyllostomidae

\section{Introduction}

Most mammals in the temperate zone breed only seasonally, and many depend upon annual changes in daylength to enforce their seasonality (e.g. Lincoln, 1981). Many species of tropical mammals also breed seasonally, but little is known about the proximate factors that enforce seasonality in these animals (reviewed by Bronson, 1989). Annual variation in daylength decreases rapidly with latitude, until it disappears at the equator. Thus, seasonality could not be enforced by photoperiod on or near the equator. It is unknown how deeply into the tropics photoperiod can be used to regulate reproduction seasonally, or what kind of cue could do so where photoperiod is constant. Although some tropical mammals can respond reproductively to changes in photoperiod

*Present address: Department of Rodent Toxicology, Huntingdon Research Centre, PO Box 2, Huntingdon, Cambridgeshire PE18 6ES, UK. 
(Petter-Rousseaux, 1972; Van Horn, 1975; Rissman et al., 1987; Sicard et al., 1988; Wayne \& Rissman, 1991), it is not known whether any use photoperiod to regulate their reproduction.

Few experimental studies have addressed these questions, and all have suffered from one or more of three deficiencies: (i) the subjects have been small, short-lived rodents or insectivores with periods of gestation short enough to permit successful opportunistic breeding without reliance on a long-term predictive cue, photoperiod or some other factor (Rissman et al., 1987; Sicard et al., 1988; Heideman \& Bronson, 1990, 1992; Wayne \& Rissman, 1991; Bronson \& Heideman, 1992); (ii) they have tested photoperiods typical of the temperate zone rather than the tropics (Rissman et al., 1987; Sicard et al., 1988); or (iii) they have involved mammals that are only marginally tropical (Petter-Rousseaux, 1970, 1972; Van Horn, 1975), and hence experience moderately large annual changes in photoperiod.

Our objectives here are twofold. First, we will describe the annual reproductive cycle of a bat, Anoura geoffroyi, from the deep tropics in Trinidad at $10^{\circ} \mathrm{N}$ latitude. This bat has a four-month gestation period, and it must therefore initiate gonadal development, and then mate, months in advance of the phase of the annual cycle of climate, food availability and other factors that are optimal for birth and lactation. This suggests strongly that these bats rely on a predictive cue of some kind to trigger gonadal development at a particular time of the year. Second, we summarize our first test of the hypothesis that the annual cycle of testicular change of this bat depends upon changes in photoperiod. Although bats constitute almost $25 \%$ of all species of mammals, the effects of photoperiod on seasonal reproduction have been examined in only two species, both from the temperate-zone. Beasley \& Zucker (1984) found that photoperiod can induce regression or development of the reproductive organ of male Antrozous pallidus. Racey (1978) concluded that there was no unequivocal evidence that increases in photoperiod regulated the testicular development in Pipistrellus pipistrellus, although he did present data suggesting that testicular development might be sensitive to particular photoperiods.

\section{Methods}

\section{Animals}

Anoura geoffroyi, Geoffroy's hairy-legged long-tongued bat, is in the family Phyllostomidae. The species feeds on nectar, pollen, soft fruit and soft-bodied insects (Goodwin, 1946; Goodwin \& Greenhall, 1961; Alvarez \& Gonzalez, 1970; Howell \& Burch, 1974; Sazima \& Sazima, 1978). Anoura geoffroyi have large eyes and presumably rely heavily on vision as well as echolocation. They are small $(12-19 \mathrm{~g})$, agile fliers and are capable of hovering flight. The species ranges from central Mexico south to Peru, Bolivia and east-central Brazil (Eisenberg, 1989). The population we examined came from Tamana Cave $\left(10^{\circ} 28^{\prime} \mathrm{N}, 61^{\circ} 12^{\prime} \mathrm{E}\right.$, elevation $\left.240 \mathrm{~m}\right)$ in central Trinidad. At Tamana Cave, $A$. geoffroyi roost in groups in chambers $15-30 \mathrm{~m}$ from the two large entrances. In these roosts, light intensity is low, but light from the entrances is apparent. Darlington (unpublished, 1970) reported that air temperature four feet above floor level in the chamber from which the bats in this study were collected averaged $25 \cdot 9 \pm 0 \cdot 3^{\circ} \mathrm{C}$, but air temperature at the ceiling may be several degrees higher. Darlington (unpublished 1970) aiso described bat activity on one night within the cave. Bats of most species (apparently including $A$. geoffroyi) were flying within the cave from about $1 \mathrm{~h}$ before sunset. Emergence from the cave began at about sunset, and all $A$. geoffroyi had left within $40 \mathrm{~min}$ of sunset. Bats returned from midnight to about dawn. The population of $A$. geoffroyi in the cave has not been censused objectively, but was of the order of several thousand individuals at the time of our studies. Goodwin \& Greenhall (1961) listed nine additional species found in the cave.

Rainfall on central Trinidad is seasonal, with a dry season typically from January to April or May, and a wet season from June to December (Fig. 1). Monthly rainfall during field data collection in 1984 and 1985 was typical (Fig. 1). Mean monthly temperature ranges from 24.6 to $26.6^{\circ} \mathrm{C}$ (Piarco Meteorological Service, Trinidad).

\section{Field data collection}

Samples of bats were collected from the walls of the cave with a hoop net monthly from September 1984 to August 1985 (Table 1). Individuals that were obviously subadult in appearance or body weight were released. In each month, the sex ratio of bats in one sample with the net was recorded. Bats were brought back to the laboratory in darkened wire mesh cages, and then held in larger $(80 \mathrm{~cm} \times 80 \mathrm{~cm} \times 80 \mathrm{~cm})$, darkened flight cages and provided with fresh fruit and water until they were killed and autopsied. Body weights were recorded for all individuals. Reproductive organs 


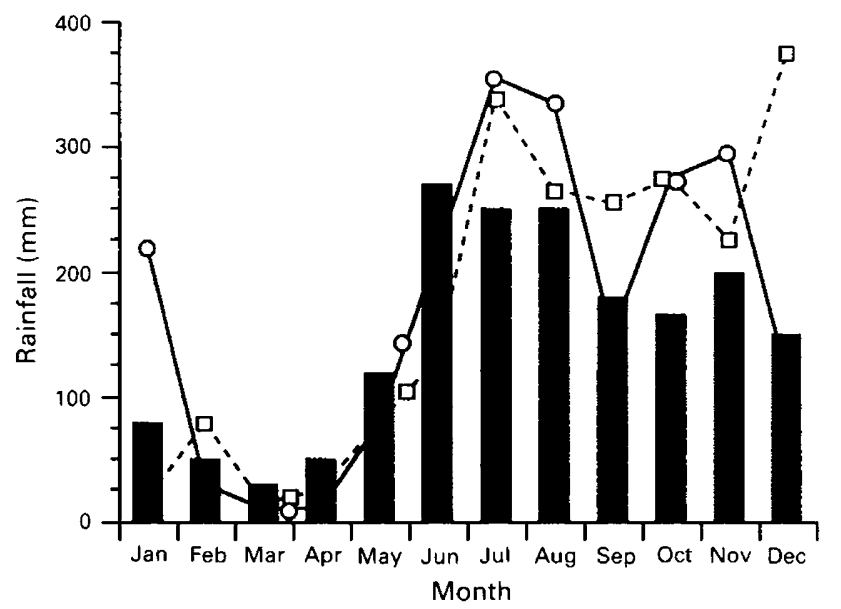

Fig. 1. Mean monthly rainfall in Central Trinidad from 1956 to $1986(\boldsymbol{\square})$, and monthly rainfall in $1984(\bigcirc)$ and in $1985(\square)$.

(paired testes with attached epididymides and uteri with attached ovaries) were removed, fixed for $18 \mathrm{~h}$ in Bouin's solution (Humason, 1972), washed twice in 50\% ethanol, stored in $70 \%$ ethanol and weighed later. Two male and two to four female reproductive tracts from each month were dehydrated in a graded alcohol series, embedded in paraplast, serially sectioned at 5-8 $\mathrm{m}$ and stained with haematoxylin and eosin, periodic-acid Schiffs Reagent or Masson's trichrome (Humason, 1972). In males, at least 60 sections evenly distributed throughout the testes were examined.

Table 1. Sample sizes, collection dates and reproductive status of Anoura geoffroyi captured in 1984 and 1985 at Tamana Cave, Trinidad

\begin{tabular}{lcccr}
\hline & \multirow{2}{*}{$\begin{array}{c}\text { Number } \\
\text { of } \\
\text { Date }\end{array}$} & \multicolumn{3}{c}{ Number of females } \\
\cline { 3 - 5 } males & Pregnant & Lactating & Total \\
\hline 1984 & & & & \\
17 Sep & 5 & 3 & 0 & 3 \\
17 Oct & 7 & 11 & 0 & 12 \\
14 Nov & 7 & 8 & 0 & 11 \\
12 Dec & 8 & 1 & 4 & 8 \\
1985 & & & & \\
16 Jan & 4 & 0 & 10 & 10 \\
13 Feb & 10 & 0 & 0 & 5 \\
20 Mar & 10 & 0 & 0 & 10 \\
16 Apr & 8 & 0 & 0 & 8 \\
22 May & 9 & 0 & 0 & 9 \\
14 Jun & 8 & 0 & 0 & 9 \\
17 Jul & 8 & 0 & 0 & 9 \\
28 Aug & 6 & 7 & 0 & 8 \\
\hline
\end{tabular}

\section{Long-term husbandry}

In October 1990, a sample of bats was collected at Tamana caves and transported to the University of Texas at Austin. Bats were housed in groups of 15 or less in light-sealed flight cages ventilated by an attached, exterior fan which pulled air in past a series of baffles, through the cage and out past another series of baffles. Each cage had a feeding and flight area $87 \mathrm{~cm}$ long, $62 \mathrm{~cm}$ wide and $55 \mathrm{~cm}$ high which was lit during part of each day. It was connected at one end by an opening $23 \mathrm{~cm}$ wide by $14 \mathrm{~cm}$ high to a roosting area $30 \mathrm{~cm}$ long, $62 \mathrm{~cm}$ wide and $55 \mathrm{~cm}$ high which received light only through the opening to the flight area. The walls and ceiling of each cage were lined with flexible 
plastic window screen. Stainless-steel trays covering the cage floors held $3 \mathrm{~cm}$ of pine shavings to absorb urine and faeces. The temperature was maintained at $30 \pm 1^{\circ} \mathrm{C}$, approximating the mean temperature of the roost area of these bats in Tamana Cave. Relative humidity was maintained at $70 \pm 10 \%$.

Light was provided by two 20-watt externally ballasted fluorescent bulbs, one at the ceiling of each end of the feeding area. Each bulb was separated from the feeding area by a translucent plastic panel. Light intensity was approximately $1000 \mathrm{~lx}$ in the flight area, but under $100 \mathrm{~lx}$ within most of the roost area. The bats roosted during the photophase on the ceiling of the roost area in positions from which the lighted exit was visible. The light intensity within the roost area was higher than those at most of the roost sites occupied by Anoura at Tamana Cave, and light intensity in the flight area approximated that at the cave entrances on clear days. The onset and end of the light period in each cage was controlled by a Hunter timer (model 41001; Hunter Fan Co., Memphis, TN, USA) programmable to the minute, and accurate to within one second per day.

The bats were fed a diet slightly modified from a formula devised by Rasweiler (1973; diet XI) for keeping bats of this family. This diet was based on peach nectar, water, high-protein baby cereal, wheat germ, whole milk powder, sucrose and supplements of protein, oils, minerals and vitamins. Rasweiler's (1973) formula included calcium caseinate, which we replaced with one half its weight of skim milk powder. Dry ingredients were mixed and stored frozen for several weeks at a time; these were mixed with the liquid ingredients and stored at $4^{\circ} \mathrm{C}$ for up to 3 days. The bats were fed within the $2 \mathrm{~h}$ before lights-off each afternoon. Food was presented ad libitum in a clean quail-watering jar placed on a $33 \mathrm{~cm}$ stand in one corner of the feeding area, near which netting was removed to prevent defaecation into the food trough by bats roosting above.

Bats were individually marked with a uniquely numbered band (1242M Monel, National Band and Tag Co., Newport, KY, USA) on a $0.8 \mathrm{~g}$ loosely-fitting stainless-steel ball chain collar (Best Chain Mfg Co., Lynwood, CA, USA) or they were tattooed (Weston Pet Supply and Manufacturing Co. Inc., Arvada, CO, USA) on the membrane of the right wing.

\section{Experimental procedure}

After their arrival in Texas, the bats were given four weeks to adjust to laboratory conditions. During this time they received a constant photoperiod of light $11.40 \mathrm{~h}$ :dark $12.20 \mathrm{~h}$, the sunrise-sunset photoperiod of Trinidad at the time of collection. After this adjustment period, three groups of males, matched for body weight and testis size, were formed. Each group was moved to a clean cage on 12 December, 1990, just before the winter solstice, and subjected to one of three photoperiod treatments. Two groups were maintained on gradually changing, civil-twilight, photoperiod schedules for $10^{\circ} \mathrm{N}$ latitude (Astronomical Almanac, 1990), and the third was maintained on a constant photoperiod. Civil-twilight photoperiods were chosen for this experiment because there is evidence that mammals may interpret the period of civil twilight just after sunset and before sunrise, during which light intensity is still high, as part of the light period (Malpaux et al., 1988). Given their large eyes and use of roosts that are exposed to light from cave entrances (Deoraj, 1987), this also seems appropriate for $A$. geoffroyi.

In one group ( $n=12$ males), the photoperiod cycle was 12 months in duration and mimicked that occurring in the wild. Photoperiod was changed in increments of $0-3 \mathrm{~min}$ at 4 day intervals. In a second group ( $n=13$ males), the cycle was identical, except that it was accelerated to 6 months in duration. In this group, photoperiod was changed at 2 day intervals, but in the same increments of $0-3 \mathrm{~min}$. In both groups, photoperiod varied from light $12.19 \mathrm{~h}$ :dark $11.41 \mathrm{~h}$ to light $13.29 \mathrm{~h}$ :dark $10.31 \mathrm{~h}$; the time of lights-off was held constant, and only the time of lights-on was varied. The initial photoperiod for these two groups was the winter solstice photoperiod: light $12.19 \mathrm{~h}:$ dark $11.41 \mathrm{~h}$. The third group ( $n=12$ males; two of these died under anaesthesia early in the study) was maintained on a constant photoperiod of light $12.54 \mathrm{~h}$ :dark $11.06 \mathrm{~h}$, the midpoint of the photoperiod schedule above. These treatments continued until 27 July, 1991, when a new experiment was designed and the treatments were altered to initiate a long-term, 3-year study.

At two-week intervals throughout the study period, each bat was anaesthetized lightly with an inhalation anaesthetic, methoxyflurane (Pitman-Moore Inc., Mundelein, IL, USA), and weighed, its scrotum was moistened with alcohol, and the greatest length and width of the right testis was measured with dial calipers. Testicular volume was then estimated using the formula for a prolate spheroid ([width $]^{2} \times$ length $\times 0.523$ ).

The accuracy of these external testis measurements was evaluated by comparing a series recorded from 15 intact bats with measurements and weights of excised testes from the same individuals. The length, width and estimated volume of testes of intact bats were highly correlated with the length, width and weight of excised testes $\left(R^{2}=0.89\right.$, $0.88,0.86$, respectively; $P<0.001$ in all cases). Body weight was not significantly correlated with testis weight $\left(R^{2}=0.04 ; P>0 \cdot 10\right)$.

\section{Data analysis}

A Student's $t$ test was used to test for differences in forearm length between sexes. A binomial test was used to test for significant departure of sex ratio from 1:1. Repeated-measures analysis of variance was used to test for differences among the groups of bats held under controlled photoperiods. One-way analyses of variance were used to test for differences among groups at each sampling point. Statistical significance was defined as probability values less than 0.05 . Means are presented with their standard errors. 


\section{Results}

\section{Field data}

Females had slightly longer forearms than males (females $42.3 \pm 0.1 \mathrm{~mm}$, males $39.9 \pm 0.3 \mathrm{~mm} ; t=6.87 ; P<0.001)$. The overall sex ratio of the captured bats was slightly biased to female, but this bias was not statistically significant ( 1 male:1.1 female; $n=192 ; P>0 \cdot 10$ ). There was no seasonal pattern of change in sex ratio in the monthly samples.

The uterus of one of four females examined histologically in July 1985 contained spermatozoa. By August 1985, seven of eight females were pregnant (Table 1) with tubal blastocysts $(n=2)$ or implanted embryos $(n=5)$. In September 1984, the crown-rump length of embryos averaged $8.7 \pm 0.3 \mathrm{~mm}$. Embryos averaged $16.8 \pm 0.4 \mathrm{~mm}$ in crown-rump length in October, and $24.0 \pm 0.9 \mathrm{~mm}$ in November; the single pregnant female captured in December had an embryo $28 \mathrm{~mm}$ long. Four lactating females captured in December carried pups $31 \pm 1 \mathrm{~mm}$ in crown-rump length. All ten females captured in January were lactating, but by 13 February none of five females captured was lactating (Table 1). All pregnancies consisted of a single embryo.

Nine of 25 females captured in mid-October 1990, and transported to Texas gave birth. Seven of their pups, born between 25 and 30 November in 1990, did not survive their first day. They ranged from $25-30 \mathrm{~mm}$ in crown-rump length. A pup born on 3 December had a crown-rump length of $33 \mathrm{~mm}$ at 12 days of age. No measurements were made on the last pup, born on 10 December, until it was two months old.

The mean weight of paired testes with attached epididymides rose from about $50 \mathrm{mg}$ from September through April to about $150 \mathrm{mg}$ from May through August (Fig. 2). Spermatogenesis was observed throughout the testes of bats captured from May to August. In addition, spermatogenesis was observed at a few sites in the seminiferous tubules of bats captured in April, at the onset of the increase in testis size, and in those captured from September to January, after testis size had decreased. There was no evidence of spermatogenesis in the testes of bats captured from October to March.

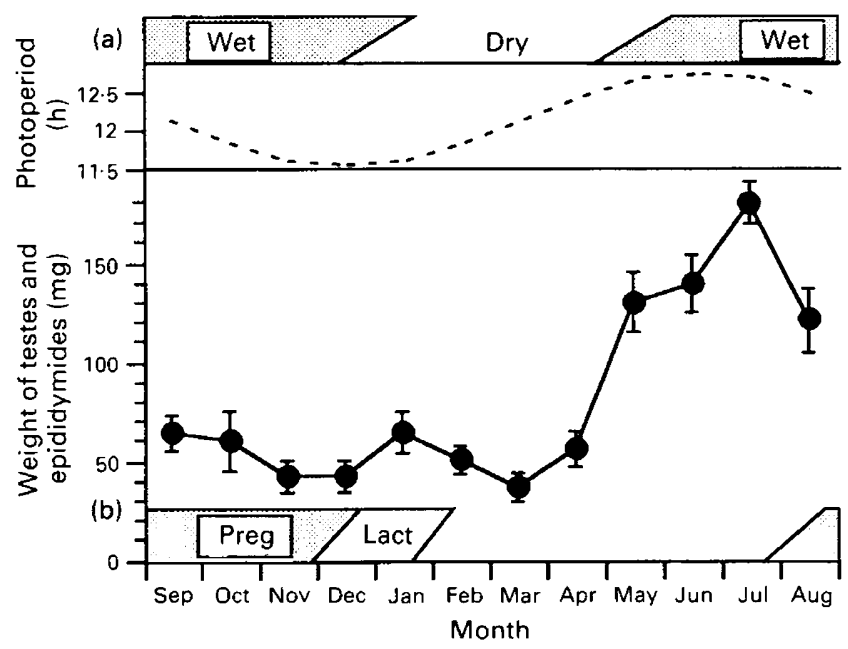

Fig. 2. Mean \pm standard error of the weight of paired testes and attached epididymides of Anoura geoffroyi from September 1984, to August 1985. (a) The typical timing of wet and dry seasons and hours of daylength (sunrise to sunset); (b) the timing of the female reproductive cycle. 


\section{Laboratory data}

In all three groups of bats, the pattern of testicular recrudescence and regression mimicked the pattern observed in the wild (Figs 2 and 3). There was a $20 \%$ increase in testis volume between January and April, and a repeated measures analysis of variance indicated that this trend was statistically significant $(F=7 \cdot 77 ; P<0.0001)$. For the full data set (January to July; later months were not included because of the change in the experimental design at the end of July), the main effect of time in a repeated measures analysis of variance was highly significant $(F=58 \cdot 27$; $P<0.0001)$. The main effect of photoperiod treatment was insignificant $(F=0.01 ; P=0.99)$, as was the interaction between the two main effects $(F=1.378 ; P=0.09)$. Thus, neither constant photoperiod from the time of the winter solstice nor acceleration of the normal photoperiod cycle to six months affected the timing of testicular recrudescence.

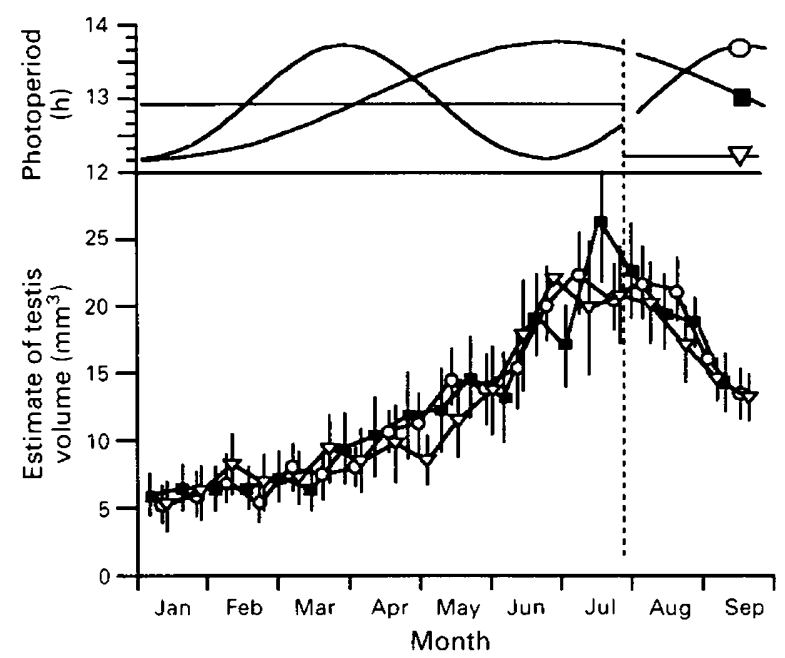

Fig. 3. Mean \pm standard error of estimated volume of right testis from groups of Anoura geoffroyi held either on constant or gradually changing photoperiods that mimicked the natural change in civil-twilight photoperiod at $10^{\circ}$ of latitude. One group $(\boldsymbol{\square} ; n=12)$ experienced a 12-month cycle of natural change, a second $(O ; n=13)$ experienced the same cycle accelerated to six months; while the third $(\nabla ; n=10)$ experienced a constant daylength. These treatments were altered in late July (- - ), after maximum testis size had been attained. The points for testis volume have been offset slightly along the $x$-axis to improve readability.

As stated earlier, this experiment was redesigned in late July to initiate a longer term, 3-year study. These changes (Fig. 3) are relevant here only to note that they occurred after maximum testis size had been achieved.

\section{Discussion}

Reproduction in Anoura geoffroyi on Trinidad is clearly seasonal in the wild. Males undergo a pronounced cycle of spermatogenesis and change in testis and epididymis weight, with a peak in July. Mating occurs in July and August, and females produce a single pup in late November or early December. Goodwin \& Greenhall (1961) reported that all 56 females captured at Tamana Cave on 20 November 1957 were pregnant with embryos in advanced stages of development. Some of these females underwent premature deliveries and the authors judged that, if the bats had been 
left undisturbed, their young would have been born about one week later. Thus, the timing of births in 1957 and 1984, among wild females, and in 1990, among laboratory-housed females with embryos conceived in the wild, was very similar. This indicates that the annual cycle of reproduction of this population was similarly timed in different years.

The duration of lactation is approximately 1.5 to 2 months. However, sampling was too infrequent and the estimate of parturition dates too broad for a precise estimate.

The period of births fell within the average transition period between the wet and dry seasons, with lactation occurring during the early dry season. In seasonal wet-tropical forests, peaks in flowering tend to occur during the dry season, while peaks in fruiting and in insect abundance generally fall in the early part of the wet season (Janzen, 1967; Croat, 1975; Buskirk \& Buskirk, 1976; Foster, 1985; Heideman, 1989). This suggests that the timing of reproduction in A. geoffroyi on Trinidad may have evolved to synchronize lactation, the period of maximum energetic demand for females, with the period of maximum abundance of nectar and pollen. Both seasonally monoestrous and seasonally polyoestrous reproductive patterns have been reported in nectarivorous members of this family of bats (Fleming et al., 1972; LaVal \& Fitch, 1977; Wilson, 1979; Willig, $1985 \mathrm{a}, \mathrm{b}$; Graham, 1989). The relationship between the timing of reproductive events and rainfall is variable for these species.

Data on the seasonal changes in testis size are unavailable for $A$. geoffroyi from other parts of their range. However, there are some data suggesting that females in populations elsewhere reproduce seasonally. In the Brazilian Caatingas, at latitude $7^{\circ} \mathrm{S}$, pregnant $A$. geoffroyi were recorded only from September to January (Willig, 1985a). Graham (1989) reported reproductive data on females captured at scattered sites in Peru. He reported pregnant females from May to August, and lactating females from June to August and in November. Unfortunately, in both of these studies, particularly the latter, some months are represented by very few or no females. Brosset \& Charles-Dominique (1990) noted that females in a colony of $A$. geoffroy $i$ had large young' in November at $4^{\circ} \mathrm{N}$ latitude in French Guiana. Several other authors, reporting on data from only one or two months at sites scattered over the geographic range of these bats, have found pregnant females in March, June or July, and lactating females in November or December (reviewed by Wilson, 1979). In general, these data suggest that seasonal breeding may be common in this species, with geographic variation in timing.

The timing of testicular recrudescence in the laboratory mimicked that in the wild, without being influenced by our experimental manipulations. We conclude, first, that the annual reproductive cycle of male $A$. geoffroyi does not require changes in photoperiod during the six months before the peak in testis size. Second, the fact that onset of testicular recrudescence could not be advanced by accelerating the rate of change in daylength suggests that the annual reproductive cycle of male $A$. geoffroyi may be insensitive to changes in photoperiod. Our results do not eliminate the possibility that photoperiod regulates the male reproductive cycle in this species. First, the reproductive cycle of these bats may resist compression into a six-month cycle, but this seems doubtful (e.g. Gwinner, 1986). Second, it is possible that our treatments did not include photoperiods both above and below a critical daylength for this species, or were of insufficient duration. We lack precise information both on the levels of light individual bats experience in the wild and on their threshold of sensitivity to light intensity. Third, photoperiod may entrain an endogenous circannual rhythm of reproduction during some other phase of the annual cycle (e.g. Malpaux et al., 1989), or these bats may have a seasonal period of refractoriness to photoperiod unrelated to circannual rhythms, as occurs in golden hamsters (e.g., Reiter, 1980; Elliott \& Goldman, 1981; Stetson \& Watson-Whitmyer, 1981; Steger et al., 1985).

In summary, $A$. geoffroyi on Trinidad have a pronounced seasonal cycle of reproduction, with births occurring at approximately the same time in each year in the wild. This cycle must be either directly driven by some environmental cue or cues other than photoperiod, or it must use an endogenous rhythm that is entrained by some environmental cue, which might or might not be photoperiod. Further work is necessary to separate these possibilities. 
We thank W. Hunte, G. Whiting and A. Kennedy for advice during the field portion of the study. J. S. Kenney, G. White, R. Mahabir and D. Peterkin were extremely helpful in the collection and transport of bats to Texas. We thank C. J. James and the staff of the Wildlife Section of the Ministry of the Environment and National Service of Trinidad for providing us with the necessary permits. The staff of the Department of Zoology of the University of the West Indies was invaluable during both portions of the study. S. A. Beckwith, K. S. Hoskins and T. Pierson provided expert assistance with bat care and data collection in Texas. This service was supported by NIH grant HD 24177 and NIH National Research Service Award F32 HD 07294.

\section{References}

Alvarez, T. \& Gonzalez, Q. (1970) Analisis polinico del contenido gastrico de murcielagos Glossophaginae de Mexico. Anales. Escuela Nacional de Ciencias Biologicas (Mexico) 18, 137-165.

The Astronomical Almanac for the Year 1990. United States Naval Observatory, Washington.

Beasley, L.J. \& Zucker, 1. (1984) Photoperiod influences the annual reproductive cycle of the male pallid bat (Antrozous pallidus). Journal of Reproduction and Fertility 70, 567-573.

Bronson, F.H. (1989) Mammalian Reproductive Biology. University of Chicago Press, Chicago. 325 pp.

Bronson, F.H. \& Heideman, P.D. (1992) Lack of reproductive photoresponsiveness and correlative failure to respond to melatonin in a tropical rodent, the cane mouse. Biology of Reproduction 46, 246-250.

Brosset, A. \& Charles-Dominique, P. (1990) The bats from French Guiana: a taxonomic, faunistic and ecological approach. Mammalia 54, 509-555.

Buskirk, R.E. \& Buskirk, W.H. (1976) Changes in arthropod abundance in a highland Costa Rican forest. American Midland Naturalist 95, 288-298.

Croat, T.B. (1975) Phenological behavior of habit and habitat classes on Barro Colorado Island (Panama Canal Zone). Biotropica 7, 270-277.

Darlington, J.P. (1970) Studies on the Ecology of the Tamana Caves with Special Reference to Cavedwelling Cockroaches. PhD dissertation, The University of the West Indies, Trinidad.

Deoraj, P. (1987) The Reproductive Biology of the Neotropical Bats Carollia perspicillata, Anoura geoffroyi and Natalus tumidirostris. M.Sc. thesis, The University of the West Indies, Trinidad.

Eisenberg, J.F. (1989) Mammals of the Neotropics: Vol. 1. The Northern Neotropics. Chicago University Press, Chicago.

Elliott, J.A. \& Goldman, B.D. (1981) Seasonal reproduction: Photoperiodism and biological clocks. In Neuroendocrinology of Reproduction, pp. 377-423. Ed. N. T. Adler. Plenum Press, New York.

Fleming, T.H., Hooper, E.T. \& Wilson, D.E. (1972) Three Central American bat communities: structure, reproductive cycles, and movement patterns. Ecology 53, 555-569.

Foster, R.B. (1985) Plant seasonality in the forests of Panama. Monographs in Systematic Botany, Missouri Botanical Garden 10, 255-262.

Goodwin, G.G. (1946) Mammals of Costa Rica. Bulletin, American Museum of Natural History 87, 275-458.
Goodwin, G.G. \& Greenhall, A.M. (1961) A review of the bats of Trinidad and Tobago. Bulletin, American Museum of Natural History 122, 191-301.

Graham, G.L. (1989) Seasonality of reproduction in Peruvian bats. Fieldiana 39, 173-186.

Gwinner, E. (1986) Circannual Rhythms. SpringerVerlag, Berlin. 154 pp.

Heideman, P.D. (1989) Temporal and spatial variation in the phenology of flowering and fruiting in a tropical rainforest. Journal of Ecology 77, 1059-1079.

Heideman, P.D. \& Bronson, F.H. (1990) Photoperiod, melatonin secretion, and sexual maturation in a tropical rodent. Biology of Reproduction 43, 745-750.

Heideman, P.D. \& Bronson, F.H. (1992) A pseudoseasonal reproductive strategy in a tropical rodent, Peromyscus nudipes: Correlates and causes. Journal of Reproduction and Fertility 95, 57-67.

Howell, D.J. \& Burch, D. (1974) Food habits of some Costa Rican bats. Revista de Biologia Tropical 21, 281-294.

Humason, G.L. (1972) Animal Tissue Techniques. W. H. Freeman and Co., San Francisco.

Janzen, D.I. (1967) Synchronization of sexual reproduction of trees within the dry-season in Central America. Evolution 21, 620-637.

LaVal, R.K. \& Fitch, H.S. (1977) Structure, movements and reproduction in three Costa Rican bat communities. Occasional Papers of the Museum of Natural History, University of Kansas 69, 1-28.

Lincoln, G.A. (1981) Seasonal aspects of testicular function. In The Testis, pp. 255-305. Eds H. Burger \& D. de Kretser. Raven Press, New York.

Malpaux, B., Wayne, N.L. \& Karsch, F.J. (1988) Termination of the breeding season in the Suffolk ewe: involvement of an endogenous rhythm of reproduction. Biology of Reproduction 39, 254-263.

Malpaux, B., Robinson, J.E., Wayne, N.L. \& Karsch, F.J. (1989) Regulation of the onset of the breeding season of the ewe: importance of long days and of endogenous reproductive rhythm. Journal of Endocrinology 122, 269-278.

Petter-Rousseaux, A. (1970) Observations sur l'influence de la photoperiode sur l'activité sexuelle chez Microcebus murinus en captivité. Annales de Biologie Animale, Biochimie, et Biophysique 10, 203-208.

Petter-Rousseaux, A. (1972) Application d'un système semestriel de variation de la photoperiode chez Microcebus murinus (Miller, 1977). Annales de Biologie Animale, Biochimie, et Biophysique 12, 367-375. 
Racey, P.A. (1978) The effect of photoperiod on the initiation of spermatogenesis in pipistrelle bats, Pipistrellus pipistrellus. In Proceedings of the Fourth International Bat Research Conference, pp. 255-258. Eds R. J. Olembo, J. B. Castelino \& F. A. Mutere. Kenya Literature Bureau, Kenya.

Rasweiler, J.J., IV (1973) Care and management of the long-tongued bat, Glossophaga soricina (Chiroptera: Phyllostomatidae), in the laboratory, with observations on estivation induced by food deprivation. Journal of Mammalogy 54, 391-404.

Reiter, R.J. (1980) The pineal and its hormones in the control of reproduction in mammals. Endocrine Review's 1, 109-131.

Rissman, E.F., Nelson, R.J., Blank, J.L. \& Bronson, F.H. (1987) Reproductive response of a tropical mammal to photoperiod. Journal of Reproduction and Fertility 81, 563-566.

Sazima, M. \& Sazima, I. (1978) Bat pollination of the passion flower, Passiflora mucronata, in south eastern Brazil. Biotropica 10, 100-109.

Sicard, B., Maurel, D., Gautun, J. \& Boissin, J. (1988) Activation ou inhibition testiculaire par la photoperiode chez plusieurs espèces de rongeurs saheliens: première mise en evidence d'une variation circadienne de la photogonadosensibilité. Comptes Rendus, Academie de Sciences (Paris) 307, 11-17.
Steger, R.W., Matt, K.S. \& Bartke, A. (1985) Neuroendocrine regulation of seasonal reproductive activity in the male golden hamsters. Neuroscience and Biobehavioral Reviews 9, 191-201.

Stetson, M.H. \& Watson-Whitmyer, M. (1981) Hormonal regulation of the annual reproductive cycle of golden hamsters Mesocricetus auratus. General and Comparative Endocrinology 45, 329-344.

Van Horn, R.N. (1975) Primate breeding season: photoperiodic regulation in captive Lemur catta. Folia Primatologica 24, 203-220.

Wayne, N.L. \& Rissman, E.F. (1991) Tropical photoperiods affect reproductive development in the musk shrew, Suncus murinus. Physiology and Behavior 50, 549-553.

Willig, M.R. (1985a) Reproductive activity of female bats from Northeast Brazil. Bat Research News 26, 17-20.

Willig, M.R. (1985b) Reproductive patterns of bats from Caatingas and Cerrado biomes in Northeast Brazil. Journal of Mammalogy 66, 668-681.

Wilson, D.E. (1979) Reproductive patterns. In Biology of Bats of the New World Family Phyllostomatidae. Part III, pp. 317-378. Ed. R. J. Baker, J. K. Jones \& D. C. Carter. Texas Tech Press, Lubbock, Texas. 441 pp.

Received 18 November 1991 